\title{
Cancer Pattern among Adults in Najran, Saudi Arabia - 2014-2019
}

\author{
Ahmed M. Badheeb ", Nadeem M. Nagi, Mohamed A. Badheeb \\ Oncology Center, King Khalid Hospital- Najran Saudi Arabia \\ Corresponding Author: Prof. Ahmed M. Badheeb, MD; badheebdr@gmail.com
}

Received: 09 October 2020;

Accepted: 23 October 2020;

Published: 26 October 2020

\begin{abstract}
Background: Najran is one of the thirteen regions in Saudi Arabia, located in the southwest of the country with a recently established oncology center and cancer registry. This paper describes for the first time the incidence of cancer in this region which has a unique geographic and demographic attribute. Methodology: This is a retrospective descriptive study that included all adult (diagnosis age $>14$ years) cancer patients captured by Najran regional cancer registry in the period of 2014 to 2019. Available data, including demographics, diagnosis, site of the tumor, and histopathology were analyzed. Pediatric malignancies were excluded. During the studied period, a regional registry was established and linked to the central Saudi Cancer Registry. All confirmed cancer cases in Najran were captured in this registry. Results: The Total number of records was 1600 diagnosed over a 6-year period (range, 200-330 per year). More females were reported (54.6\%) than males (45.4\%). The median age was 52 years $(\mathrm{SD}, \pm 19)$. The three most common cancers were breast $(14.2 \%)$, thyroid $(11.8 \%)$, and Colorectal $(8.4 \%)$. Among the females, breast $(25.3 \%)$ was the most common cancer followed by thyroid $(16.7 \%)$, and colorectal $(7 \%)$; while in males, colorectal cancers (10.2\%), hepatocellular carcinoma (6.7\%), and leukemia (6.6) were the most common. Conclusions: Breast cancer in females and colorectal cancer in males were the most frequent types of solid malignancies in Najran, Saudi Arabia. Our study shows that the pattern of cancers bears some similarities with the national and Gulf data with some differences that warrant further exploration.
\end{abstract}

Keywords: Saudi Cancer Registry, Incidence, Najran, Saudi Arabia

\section{Introduction}

Cancer is a leading cause of death worldwide in countries of all income levels. The incidence and mortality are expected to increase rapidly as populations grow, age, and adopt lifestyle risk factors that increase cancer risk such as tobacco use, physical inactivity, obesity, and reproductive patterns are increasingly worldwide ${ }^{[1]}$.

"In 2018, cancers accounted for over 9.6 million deaths and there were more than 18.1 million new cases worldwide. The most commonly diagnosed cancers worldwide are lung, breast, and colorectal cancers. The most common causes of cancer death are lung, stomach, and liver cancers "(The International Agency for Research on Cancer 2018) ${ }^{[2]}$.

In Saudi Arabia, breast, colorectal cancers are the commonest type of cancers followed by the thyroid, Non-Hodgkin lymphoma, and leukemia ${ }^{[3]}$.

The aim of this paper is to describe the pattern of cancer in Najran region and to explore the association with age, sex, and site of cancer according to the international classification of disease (oncology).

\section{Materials and Methods}

This is a retrospective descriptive study that included all adult (diagnosis age $>14$ years) cancer patients captured by Najran regional cancer registry in the period of 2014 - to 2019. Available data, including demographics, diagnosis, site of tumor, and histopathology was analyzed. Pediatric malignancies were excluded. During the studied period, a regional registry was established and linked to the central Saudi Cancer Registry. All confirmed cancer cases in Najran, were captured in this registry.

The cancers were arranged according to the affected organ to specify the most affected site in both males and females. The data were analyzed to find percentages, means, and standard deviations. All confirmed cancer cases that from Jan 2014 to December 2019 were revised retrospectively. The cases identified from the cancer registry. Demographic, clinical, and histopathological data had been collected.

\section{Results}

The Total number of cases was 1600 for the period 2014-2019. Cancer was more frequent in females $(54.6 \%)$ than males $(45.4 \%)$ (figure1). 


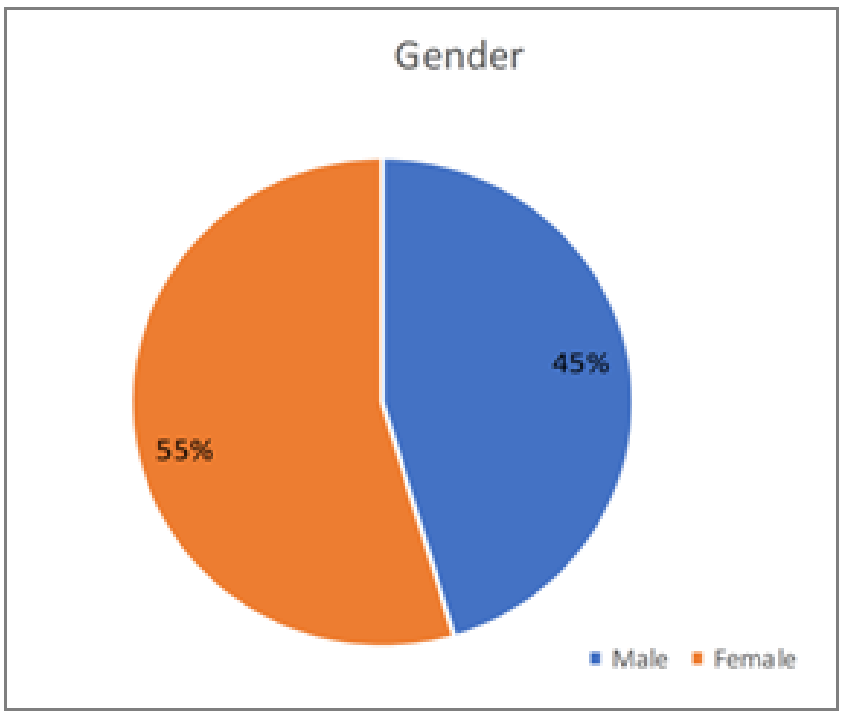

Figure: Distribution of cases by sex

The median age was 52 years with a standard deviation (SD) of 19 . The three most common cancers were breast (14.2\%), thyroid (11.8\%), and Colorectal (8.4\%). Among the females, breast (25.3\%) was the most common cancer followed by thyroid $(16.7 \%)$, and colorectal (7\%). On the other hand, colorectal cancers (10.2\%), hepatocellular carcinoma (6.7\%), and leukemia (6.6) were the most prevalent among males. The five most common types were breast $(14.2 \%)$, thyroid $(11.8 \%)$, and Colorectal $(8.4 \%)$, gastric $(4.8 \%)$, and leukemia $(4.7 \%)$. (Table 1$)$

Table 1: The 10 Most Common Cancers

\begin{tabular}{|l|l|l|l|}
\hline & Site of Cancer & Number & \% of all sites \\
\hline 1 & Breast & 228 & 14.2 \\
\hline 2 & Thyroid & 189 & 11.8 \\
\hline 3 & Colorectal & 135 & 8.4 \\
\hline 4 & Gastric & 77 & 4.8 \\
\hline 5 & Leukemia & 75 & 4.7 \\
\hline 6 & NHL & 74 & 4.6 \\
\hline 7 & Liver & 72 & 4.5 \\
\hline 8 & Head \& Neck & 56 & 3.5 \\
\hline 9 & Pancreas & 55 & 3.4 \\
\hline 10 & Brain & 53 & 3.3 \\
\hline & All sites total & 1600 & $100.0 \%$ \\
\hline
\end{tabular}

Regarding topographic distribution by sex, the five major cancers in males were colorectal (10.2\%), liver (6.7), leukemia (6.6\%), NHL $(6.2 \%)$, \& gastric $(6.1 \%)$, (Table 2), while in females, the most common cancers were breast $(25.3 \%)$, thyroid $(16.7 \%)$, colorectal (7\%), ovarian(5.8\%), and gastric (3.8\%) (Table:3).

Table 2: The 10 Most Common Male Cancers

\begin{tabular}{|l|l|l|}
\hline & Site of Cancer & \% of all sites \\
\hline 1 & Colorectal & 10.2 \\
\hline 2 & Liver & 6.7 \\
\hline 3 & LEUKEMIA & 6.6 \\
\hline 4 & NHL & 6.2 \\
\hline 5 & Gastric & 6.1 \\
\hline 6 & THYROID & 5.9 \\
\hline 7 & HEAD \& NECK & 5.8 \\
\hline 8 & BLADDER & 5.6 \\
\hline 9 & Brain & 4.7 \\
\hline 10 & Pancreatic & 4.4 \\
\hline
\end{tabular}

Table 3: The10 Most Common Female Cancers

\begin{tabular}{|c|l|l|}
\hline & Site of Cancer & \% of all sites \\
\hline 1 & Breast & 25.3 \\
\hline 2 & THYROID & 16.7 \\
\hline 3 & Colorectal & 7.0 \\
\hline 4 & OVARIAN & 5.8 \\
\hline 5 & Gastric & 3.8 \\
\hline 6 & Uterine & 3.4 \\
\hline 7 & NHL & 3.3 \\
\hline 8 & LEUKEMIA & 3.1 \\
\hline 9 & Hodgkin's Lymphoma & 2.7 \\
\hline 10 & Liver & 2.6 \\
\hline
\end{tabular}

\section{Discussion}

This study was performed to analyze the incidence of cancer among adults at Najran region in Saudi Arabia constitutes of six governorates (Najran, Sharourah, Yadama, Thar, Haboona, \& Badr-Aljanoob) with a population of 408,272 according to "2010 census" ${ }^{[4]}$.

The results of our study showed that the malignancies were more frequent in females (54.6\%) than males $(45.4 \%)$, and this is similar to the National Saudi Cancer registry data were the females $(53.8 \%)$ while the males $(46.2 \%)$.

The top ten cancers in this study were breast, thyroid, colorectal, gastric, leukemia, Non-Hodgkin's Lymphoma, liver, head \& neck, pancreas, and brain. There is a similarity in the incidence of breast cancer (the first) \& leukemia (the fifth position) with the Saudi cancer registry 2015 and the Gulf Cooperation Council (GCC) results ${ }^{[5,6]}$.

Thyroid cancer as the fastest growing cancer in terms of its incidence comes as the second common cancer (11.8\%) which is higher than the national $(8.5 \%)$, GCC $(6.3 \%)$, and the international figures, this may be related to two factors, the first one is the overdiagnosis by the fine needle aspiration biopsy, while the second possible cause is the low iodine intake in Najran region as showed in meta-analysis where a higher intake of dietary iodine was as a protective factor against thyroid cancer ${ }^{[7-9]}$.

Although our study showed a lower incidence of the colorectal $(8.4 \%)$ in comparison with the national figure of $12.2 \%$ we are in concordance with the GCC (9\%) and the world (10\%).

Gastric cancer ranked as the fourth $(4.8 \%)$, while not seen among the top 10 national cancers, but we are again in concordance with the GCC, where the gastric cancer is the 8th one $(3.4 \%)$ and all over the world as the fifth $(5.7 \%)^{[10]}$.

The most commonly diagnosed cancer worldwide is the lung cancer, while our study showed a low incidence of this cancer (2.8\%) mostly as a result of the lower prevalence of tobacco smoking in Najran in contradictory to the higher prevalence of tobacco chewing that may explain the higher incidence of head \& neck cancer (8th, 3.5\%) as a unique finding differs from the local $\&$ worldwide figures ${ }^{[11]}$.

Our study showed pancreatic cancers among the top ten with global similarity where about 338000 people had pancreatic cancer in 2012 worldwide, making it the 11th most common cancer. To date, the causes of pancreatic cancer are still insufficiently known, although certain risk factors have been identified, such as smoking, obesity, genetics, diabetes, diet, inactivity. Our figures are higher than the national and GCC figures, this warrants further exploration ${ }^{[9]}$.

In males, the incidence of male genital system malignancies (including prostate cancers), like other Arabian Gulf and Asian countries, is very low compared to Western despite the 
high intake of calories and high consumption of animal fat ${ }^{[12-14]}$. This may be attributed to the lack of prostate screening programs [15].

\section{Conclusion}

In conclusion, breast cancer in females and colorectal cancer in males were the most frequent types of solid malignancies in Najran, Saudi Arabia. Our results generally indicate that the pattern of the most common registered cancer bears some similarities with the national and Gulf data with some differences that warrant further exploration.

\section{Ethics approval and consent to participate}

This study was conducted after approval of the Cancer Research Committee in the oncology Department at King Khalid Hospital in Najran. No informed consent needed for this type of study with no extra burden for participants and anonymized data.

\section{Data Availability}

Data are available at Saudi Cancer Registry - Najran and it will be included in the periodic report of the national registry.

\section{Conflicts of Interest}

The authors declare that there is no conflict of interest regarding the publication of this paper.

\section{Funding Statement}

The research and publication of this article was self-funded.

\section{Authors' contributions}

$\mathrm{AB}$ analyzed and interpreted the patient data. $\mathrm{NN}$ and $\mathrm{MB}$ performed were contributors in writing the manuscript. All authors read and approved the final manuscript.

\section{Acknowledgments}

The authors would like to acknowledge Mrs. Rahma Mabkhoot at the Saudi Cancer Registry Office, King Khalid Hospital - Najran for her cooperation, to Dr. Iyad Sultan for reviewing the paper, and to the colleagues in the oncology team for caring for cancer patients and to their families.

\section{References}

[1] Torre L. A., Siegel R. L., Ward E. M., et al.: Global Cancer Incidence and Mortality Rates and Trends--An
Update: a publication of the American Association for Cancer Research, cosponsored by the American Society of Preventive Oncology. Cancer Epidemiology Biomarkers \& Prevention. 2016, 25:16-27. 10.1158/1055-9965.epi-15-0578

[2] Stewart B, Wild C.: World Cancer Report 2014. Published online. Int Agency Res Cancer. 2014,

[3] Akhtar SS, Reyes LM: Cancer in Al-Qassim, Saudi Arabia: A retrospective study (1987-1995). Ann Saudi Med. Published online. 1997, 10.5144/02564947.1997.595

[4] General Authority for statistics. Establishments Census 2010. (2010). Accessed: July 2020: https://saudicensus.sa/en/content/establishments-census2010.

[5] Saudi Health council. Cancer incidence report in. Saudi Arabia. 2015. Saudi, 2015:10-17. 10.1145/3132847.3132886

[6] Al-Madouj, Eldali, \& Al-Zahrani: Ten Year Cancer Incidence among Nationals of the GCC States (19982007). Gulf Center for Cancer Control and Prevention (GCCCP). 2011, 113-131.

[7] World Health Organization - Cancer Fact Sheets. (2018). Accessed: July 2020: https://www.who.int/newsroom/fact-sheets/detail/cancer.

[8] Cao LZ, Peng XD, Xie JP, Yang FH, Wen HL, Li S: The relationship between iodine intake and the risk of thyroid cancer. Med (United States). Published online. 2017. 10.1097/MD.0000000000006734

[9] Ilic M, Ilic I: Epidemiology of pancreatic cancer. World J Gastroenterol. Published online. 2016, 10.3748/wjg.v22.i44.9694

[10] Rawla P, Barsouk A.: Epidemiology of gastric cancer: Global trends, risk factors and prevention. Prz Gastroenterol. 2019., 14:26-38. 10.5114/pg.2018.80001

[11] Alberg AJ, Brock M V., Ford JG, Samet JM, Spivack SD. : Epidemiology of lung cancer: Diagnosis and management of lung cancer, 3rd ed: American College of Chest Physicians evidence-based clinical practice guidelines. Chest. 2013, 143:10.1378/chest.12-2345

[12] Ba Saleem HO, Bawazir AA, Moore M, Al-Sakkaf KA: Five years cancer incidence in Aden cancer registry, Yemen (2002-2006). Asian Pacific J Cancer Prev. 2010, 11:507-511.

[13] Jamal S, Moghal S, Mamoon N, et al.: The pattern of malignant tumours: Tumour registry data analysis, AFIP, Rawalpindi, Pakistan (1992-2001). J Pak Med Assoc. Published online. 2006, 56:

[14] Ghafoor M, Schuyten R, Bener A: Epidemiology of Prostate Cancer in United Arab Emirates. Med J Malaysia. Published online. 2003, 58:712-716.

[15] Rawla P.: Epidemiology of Prostate Cancer. World J Oncol. 2019, 10:63-89. 10.14740/wjon1191 